\title{
IN VITRO ANTIOXIDANT ACTIVITY STUDIES OF AQUEOUS- AND FREEZE-DRIED FRUIT EXTRACT OF RHUS CHINENSIS AND JUICE OF CITRUS MACROPTERA, THEIR COMPARATIVE STUDIES
}

\author{
SETINGLA SANGTAM*, THANZAMI K \\ Department of Pharmacy, Regional Institute of Paramedical and Nursing Science, Mizoram, Aizawl, India. Email: setinglasangtam@gmail.com \\ Received: 06 June 2020, Revised and Accepted: 05 August 2020
}

\section{ABSTRACT}

Objectives: The objective of the study is to evaluate in vitro antioxidant activity of aqueous- and freeze-dried fruits extracts of Rhus chinensis and Citrus macroptera and their comparative studies.

Methods: The sumac fruit extracts were prepared by macerating in distilled water for $36 \mathrm{~h}$, strained, and concentrated. Hatkora juice was used as it is for further concentration. Both the sample were dried using two methods, that is, evaporation in the water bath at $50^{\circ} \mathrm{C}$ and freeze-dried in a lyophilizer. The total phenolic content and total flavonoid content were determined using Folin-Ciocalteu and aluminum chloride method. The extracts were evaluated for antioxidant activity by 2, 2-diphenyl-1-picrylhydrazyl (DPPH) free radical scavenging assay and reducing power assay.

Results: Both sumac extract and Hatkora juice show potent antioxidant activity. When compared, the freeze-dried sample shows better activity as compared to the aqueous dried sample in both DPPH and reducing power assay.

Conclusions: This study result shows high phenolic and flavonoid content which is responsible for its high antioxidant activity. This suggests that the fruits can be viewed as a potential source of natural antioxidants that can provide valuable functional ingredients useful for the prevention of diseases related to oxidative stress, dietary supplements, functional food, nutraceuticals, etc.

Keywords: Antioxidant, Rhus chinensis, Citrus macroptera, Nutraceuticals.

(c) 2020 The Authors. Published by Innovare Academic Sciences Pvt Ltd. This is an open access article under the CC BY license (http://creativecommons. org/licenses/by/4. 0/) DOI: http://dx.doi.org/10.22159/ajpcr.2020.v13i10.38650

\section{INTRODUCTION}

\section{Nutraceuticals}

The term nutraceuticals were derived from the word "nutrition" and "pharmaceutical" by Stephen Defelice in 1989 [1]. Nutraceuticals provide medicinal or health benefits, including the prevention and/or treatment of diseases [2]. Plants are the abundant reservoir of medicinal drugs used both in traditional and modern health-care systems, nutraceuticals, food supplements, pharmaceutical industries, and eccentric chemicals for synthetic drugs [3]. Nutraceutical is preferred over conventional medicines as it avoids that side effects have naturally dietary supplements, dietary fiber, etc. According to the W.H.O, over $80 \%$ of the world's populations rely on such traditional plant-based systems of medicine as phytochemicals, nutritional constituents, or as functional food [4]. According to the global nutraceuticals market (2017-26), estimated to be $\$ 379.06$ billion in 2017 and expected to expand at a rate of $7.6 \%$ to reach $\$ 734.60$ billion by 2026 [5]. At present, the market is obsessed with nutraceuticals by the aging population, rising health-care costs, advances in food technology, and nutrition, as well as helps in better increasing understanding of the link between diet and health by the growing consumer [6].

Oxidative damage to cellular biomolecules such as lipids, proteins, and DNA plays a crucial role in the development of degenerative diseases and pathogenesis of diabetes, cardiovascular diseases, nephrotoxicity, hepatotoxicity, inflammations, cancer, and in the process of aging [7]. The effects of free radicals on human beings are strongly linked to toxicity, disease, and aging and are linked with the evolvement of degenerative ailments [8]. Almost all the living species have their defense system to protect themselves from oxidative stress produced by reactive oxygen species [9]. Antioxidants can greatly reduce the damage due to oxidants by neutralizing the free radicals before they can attack the cells and preventing damage to lipids, proteins, enzymes, carbohydrates, and DNA [10].

\section{METHODS}

Chemicals used

Aluminum chloride $\left(\mathrm{AlCl}_{3}\right)$, Aluminium nitrate, Ascorbic acid (SigmaAldrich), Butylated hydroxyl anisole (Merck) (Loba Chemie), Carboxy, 2,2-Diphenyl-1-picrylhydrazyl (Himedia), Diethyl-ether(Merck) Disodium hydrogen phosphate (Nice Chemicals Pvt Ltd), Ethanol (Merck), Ferric chloride (Qualigens), Folin Ciocaltue reagent, Gallic acid, Hydrochloric acid (Merck), Isosaline, Methanol, Normal saline, Phosphate buffer saline, Potassium dihydrogen phosphate (Merck), Potassium Ferricyanide(Nice Chemicals Pvt. Ltd.), Sodium carbonate, Sodium chloride(Sd Fine-chem Ltd.), Sodium hydroxide, Sodium nitrite $\left(\mathrm{NaNO}_{2}\right)$, Trichloroacetic acid(Merck), and distilled water were used.

\section{Instrument used}

Ultraviolet(UV)-visible spectroscopy (Thermo Fisher), Lyophilizer (Mini Lyodel), water bath (WEIBER), weighing balance (Denver Instrument).

\section{Methodology}

Collection of plant samples

The two samples selected sumac fruits and Hatkora juice were bought from the local market within Aizawl, Mizoram.

\section{Identification of plants}

The plant sumac/khawmhma was collected during its fruiting season during the month of November-December, herbarium sheet was prepared and was authenticated at the Botanical Survey of India, Kolkata, the specimen was numbered as LH-01. Hatkora was also 
collected during the flowering season March-April and fruiting season October-December, herbarium sheet was prepared and was authenticated at the Department of Forestry, Mizoram University, and the specimen was numbered as IBT-02. Both specimens were submitted at the Department of Pharmacy, RIPANS, for future reference.

\section{Plant sample extraction}

Dried sumac fruits were first ground into a fine powder, macerated with water for $36 \mathrm{~h}$, and strained. After straining, the aqueous part of sumac and Hatkora juice was concentrated and dried using two ways, that is, evaporation from water bath at $50^{\circ} \mathrm{C}$ and freeze-drying by lyophilizer.

\section{Determination of total phenolic content (TPC)}

The TPC of the samples was determined using the Folin-Ciocalteu method [11]. The calibration curve was prepared by mixing $1 \mathrm{ml}$ of methanolic solution of gallic acid 20,40,60,80, and $100 \mu \mathrm{g} / \mathrm{ml}$ with $5 \mathrm{ml}$ Folin-Ciocalteu reagent (diluted tenfold). After $3 \mathrm{~min}, 4 \mathrm{ml}$ of sodium carbonate solution $(0.7 \mathrm{M})$ was added, and the mixture was allowed to stand for $1 \mathrm{~h}$ at room temperature. Absorbance was measured at $765 \mathrm{~nm}$ using a UV-visible spectrophotometer. From $50 \mu \mathrm{g} / \mathrm{ml}$ of sample, $1 \mathrm{ml}$ was also mixed with the reagents above, and after $1 \mathrm{~h}$, the absorbance was measured to determine total plant phenolic content. From the calibration curve, the amount of phenolic compounds was determined and expressed as milligrams of Gallic acid equivalent (GAE)/g of the dried extract.

\section{Determination of total flavonoid content (TFC)}

The TFC of the methanol extract was determined by the $\mathrm{AlCl}_{3}$ method [12]. From $50 \mu \mathrm{g} / \mathrm{mL}$ of extract, $1 \mathrm{ml}$ was mixed with $2 \mathrm{ml}$ of distilled water. After $5 \mathrm{~min}, 3 \mathrm{ml}$ of $5 \% \mathrm{NaNO}_{2}$ and $0.3 \mathrm{ml}$ of $10 \% \mathrm{AlCl}_{3}$ were added. After $6 \mathrm{~min}, 2 \mathrm{ml}$ of $\mathrm{NaOH}(1 \mathrm{M}$ ) was added, and the volume was made up to $10 \mathrm{ml}$ with distilled water. After $1 \mathrm{~h}$, absorbance was measured at $510 \mathrm{~nm}$. A standard curve was prepared with quercetin at different concentrations $(20,40,60,80$, and $100 \mu \mathrm{g} / \mathrm{ml})$. From the calibration curve of the reference standard, the TFC was determined and expressed as milligrams of quercetin equivalent $(\mathrm{QE} / \mathrm{g})$ of the dried sample.

\section{2, 2-diphenyl-1-picrylhydrazyl (DPPH) radical scavenging activity assay}

The radical scavenging effect of the samples was estimated based on stable DPPH free radical [11]. Butylated hydroxyanisole (BHA) was used as the reference standard. $0.5 \mathrm{ml}$ of DPPH solution in methanol $(0.1 \mathrm{mM})$ was mixed with $3 \mathrm{ml}$ of the extract and $3 \mathrm{ml}$ of a standard prepared in various concentrations ranging from $2 \mu \mathrm{g} / \mathrm{ml}$ to $10 \mu \mathrm{g} / \mathrm{mL}$, respectively. The sample and standards were incubated for $30 \mathrm{~min}$ at $37^{\circ} \mathrm{C}$. Absorbance was measured at $517 \mathrm{~nm}$ using a UV-visible spectrophotometer. Control reading was also taken. The scavenging effect of DPPH free radical was calculated using the following equation;

$$
\% \text { DPPH radical scavenging }=\frac{\text { Control }- \text { Absorbance }}{\text { Control }} * 100
$$

\section{Determination of reducing power assay}

The reducing power of the sample was determined using ascorbic acid as standard [11]. $1 \mathrm{ml}$ each of the sample and standard with various concentrations ranging from $20 \mu \mathrm{g} / \mathrm{ml}$ to $100 \mu \mathrm{g} / \mathrm{ml}$ was mixed with $2.5 \mathrm{ml}$ of phosphate buffer $(6.6 \mathrm{pH})$ and $2.5 \mathrm{ml}$ of $1 \%$ potassium ferricyanide. The mixture was then incubated at $50^{\circ} \mathrm{C}$ for $30 \mathrm{~min}$. The reaction was stopped by adding $2.5 \mathrm{ml}$ of $10 \%$ trichloroacetic acid and the mixture was centrifuged at $3000 \mathrm{rpm}$ for $10 \mathrm{~min} .2 .5 \mathrm{ml}$ of the supernatant was added in $2.5 \mathrm{ml}$ of distilled water, mixed $0.5 \mathrm{ml}$ of $0.1 \%$ ferric chloride solution. The absorbance was measured at $700 \mathrm{~nm}$ using a UV-visible spectrophotometer. Higher absorbance of the reaction mixture indicated that the reducing power was increased.

\section{RESULTS}

\section{TPC and TFC}

As seen in Table 2, the TPC content for aqueous-dried Rhus chinensis and Citrus macroptera was 216.26 and $102 \mathrm{mg} \mathrm{GAE} / \mathrm{g}$ of the extract, while it is higher at freeze-dried one, that is, 258.66 and $104.26 \mathrm{mg} \mathrm{GAE}$. The TFC content for freeze-dried was higher for both $R$. chinensis and C. macroptera, that is, 53.34 and $198.66 \mathrm{mg} \mathrm{QE} / \mathrm{g}$ of extract, whereas for aqueous-dried R. chinensis and C. macroptera, it was found to be 26.667 and $176 \mathrm{mg} \mathrm{QE} / \mathrm{g}$ of extract. The TPC was found higher in R. chinensis extract, while TFC was found to be higher in $C$. macroptera.

\section{In vitro antioxidant activity study}

DPPH radical scavenging activity assay

Fig. 1 shows the comparison of radical scavenging activities of the different samples with standard compound BHA. The IC $_{50}$ values for each sample are calculated and are given in Table 3.

All value is represented as Mean \pm SEM, $n=3$. One-way analysis of variance followed by Dunnett's test was performed as the significance. The minimum value of ${ }^{*} \mathrm{p}<0.05$ considered as significant, ${ }^{* *} \mathrm{p}<0.01$, and ${ }^{* * *} \mathrm{p}<0.001$ as compared with the control group.

\section{Determination of reducing power assay}

The reducing power of each sample is determined and compared with standard compound ascorbic acid and is given in Fig. 2

All value is represented as Mean $\pm S E M, n=3$.

Table 1: List of fruits selected for the experiment

\begin{tabular}{|c|c|c|}
\hline Family & Anacardiaceae & Rutaceae \\
\hline Genus & Rhus & Citrus \\
\hline Species & Chinensis & C. macroptera \\
\hline Binomial name & Rhus chinensis Mill & $\begin{array}{l}\text { Citrus macroptera } \\
\text { Montrouz }\end{array}$ \\
\hline Synonyms & $\begin{array}{l}\text { Rhus javanica auct, } \\
\text { Rhus semialata Murray }\end{array}$ & $\begin{array}{l}\text { C. aurantium, C. papuana } \\
\text { F. M. Bailey }\end{array}$ \\
\hline Common name & Sumac & Hatkora \\
\hline
\end{tabular}

Table 2: Phenolic and flavonoid content of the sample

\begin{tabular}{lll}
\hline Sample & TPC $(\mathbf{m g ~ G A E} / \mathbf{g})$ & TFC $(\mathbf{m g ~ Q E} / \mathbf{g})$ \\
\hline ARC & 216.26 & 26.667 \\
FRC & 258.66 & 53.34 \\
ACM & 102 & 176 \\
FCM & 104.26 & 198.66 \\
\hline
\end{tabular}

ARC: Aqueous-dried Rhus chinensis, FRC: Freeze-dried Rhus chinensis, Aqueousdried Citrus macroptera, FCM: Freeze-dried Citrus macroptera. GAE: Gallic acid equivalent

Table 3: IC $_{50}$ value of ARC, FRC, APE, FPE, ACM, FCM, and BHA

\begin{tabular}{llllll}
\hline Sample & BHA & FRC & ARC & FCM & ACM \\
\hline $\mathrm{IC}_{50}(\mu \mathrm{g} / \mathrm{ml})$ & 2.463 & 3.282 & 3.792 & 12.799 & 13.489
\end{tabular}

BHA: Butylated hydroxyanisole, ARC: Aqueous-dried Rhus chinensis, FRC: Freeze-dried Rhus chinensis, Aqueous-dried Citrus macroptera FCM: Freeze-dried Citrus macroptera

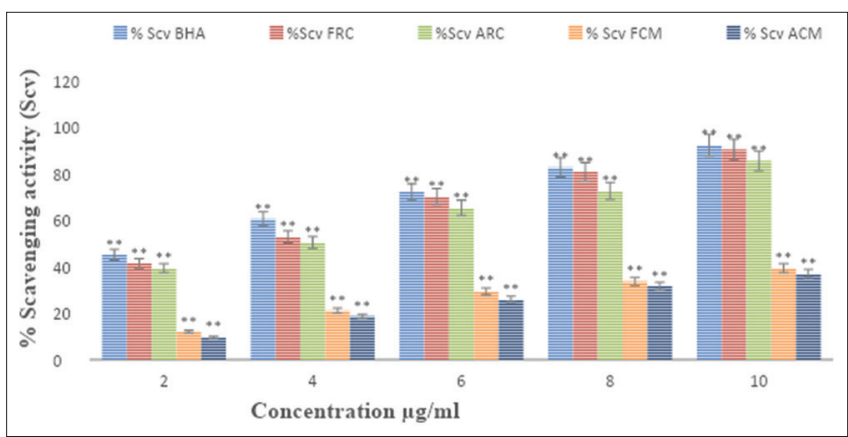

Fig. 1: Comparative study of the 2, 2-diphenyl-1-picrylhydrazyl scavenging activity of the freeze- and aqueous-dried fruit extracts Rhus chinensis and Citrus macroptera juice 


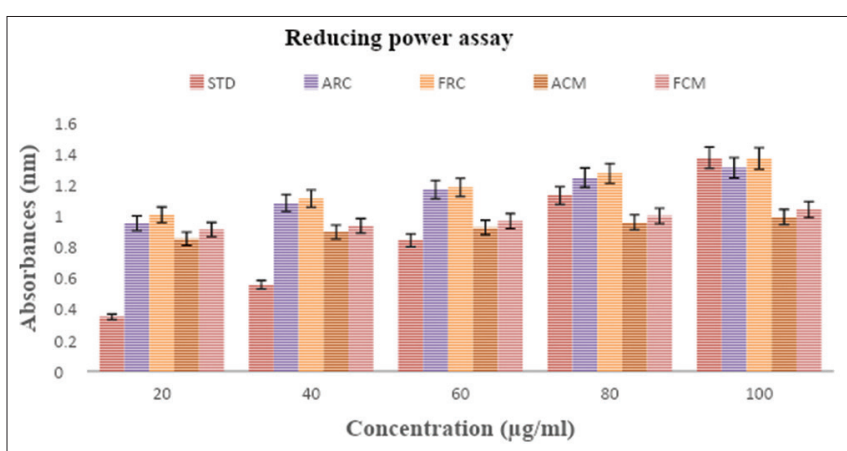

Fig. 2: Comparative study of the reducing power assay of the freeze-and aqueous-dried fruit extracts of Rhus chinensis and Citrus macroptera juice

\section{DISCUSSION}

The total phenolic and flavonoid of the aqueous- and freeze-dried fruit extracts of R. chinensis and C. macroptera juice were determined from the calibration curve of gallic acid $(y=0.0123 x+0.046)$ and quercetin $(y=0.0015 x+0.0371)$. The phenolic content of the freeze-dried and aqueous-dried extracts is given in Table 2 which signifies their high phenolic and flavonoid content. The phenolic content was found higher in freeze-dried $R$. chinensis fruit extract and lower in aqueous-dried C. macroptera. The flavonoid content was found higher in freeze-dried C. macroptera and lower in aqueous-dried R. chinensis. When compared, the freeze-dried fruit extracts show higher phenolic and flavonoid content than aqueous-dried fruit extracts. Phenolics and flavonoids have been considered to be one of the main phytochemicals responsible for the antioxidant capacity of fruits and vegetables. Plant-derived polyphenols display characteristic inhibitory patterns toward oxidative reactions in vitro and in vivo [11]. Flavonoids are among one of the most abundant and widespread groups of natural compounds as well as are considered the largest and most important group of natural occurring phenolic compounds [13]. From the amount of phenols and flavonoid content, it is apparent that the sample may possess good antioxidant activities. Recently, many research studies had shown that phenolic content in plants could be a tie into their antioxidant activities and its phenolic and polyphenol compounds can act as an antioxidant [14].

In DPPH radical scavenging assay, the free radical is scavenged by antioxidants through the donation of electrons forming the reduced DPPH. The DPPH scavenging effects of phenolic compounds are presumed to be due to their hydrogen donating ability [15]. The inhibition concentration $\left(\mathrm{IC}_{50}\right)$ parameter was used for the interpretation of the results from the DPPH method. $\mathrm{IC}_{50}$ is defined as the concentration in $\mu \mathrm{g} / \mathrm{mL}$ of the extract to scavenge $50 \%$ of the DPPH radical and lower $\mathrm{IC}_{50}$ values indicate higher antiradical activity [16]. The percentage inhibition and the dose-response of extracts and standard are shown in Fig. 1. All the extracts were made in the least concentration, that is, $2,4,6,8$, and $10 \mu \mathrm{g} / \mathrm{ml}$. The $\mathrm{IC}_{50}$ of the freeze-dried fruits extract of $R$. chinensis was found to be lower and higher in aqueous-dried C. macroptera compared to standard (BHA), as given in Table 3. The low $\mathrm{IC}_{50}$ value of freeze-dried extract of $R$. chinensis indicates high free radical scavenging activity that is almost similar to the standard compound. It is also clear that freeze-dried extracts exhibit better scavenging activity than that of aqueous-dried extract.

Wong, in 2013, studied the evaluation of natural phenolic antioxidants in traditional Chinese medicines as carbohydrate absorption modulators for the potential development of anti-hyperglycemic functional foods and found that extract of Chinese galls from Rhus chinensis exhibited highest TPC, antioxidant capacity, and $\alpha$-amylase inhibitory activities [17]. Hasan et al., in 2018, investigated the protective effect of Citrus macroptera fruit pulp juice rendering Nrf2-pathway against cisplatin-induced genotoxicity and study suggested that $C$. macroptera is very much effective against oxidative stress. Therefore, $C$. macroptera fruit juice can probably be a potential dietary source of antioxidants and also can be used to fight against genotoxicity induced by either cisplatin or any other genotoxic chemical [18].

In reducing power assay, reducing ability was measured by the change of $\mathrm{Fe}^{3+}$ to $\mathrm{Fe}^{2+}$, and color changes from yellow to dark green when the reaction took place. The absorbance of readings kept raising with an increase in concentration which signifies that the extracts have a good reductive potential and electron donor ability for stabilizing free radicals. The elevation in absorbance indicates an increased reducing the power of the extracts $[19,20]$. The reducing power of the plant extract was compared to the standard ascorbic acid and their comparison chart is shown in Fig. 2. It is observed that there is a significant elevation in absorbance of the standard with an increase in concentration (conc.), whereas the extracts show fewer differences. It is seen that the reducing power of all samples was better than the standard compound, especially at a lower concentration. Their reducing power does not seem to be concentration-dependent, while the reducing power of ascorbic acid is clearly dependent on concentration. The freeze-dried fruit extract of $R$. chinensis showed the highest reducing power and lowest in aqueous-dried C. macroptera juice when compared with standard (ascorbic acid). The freeze-dried extracts give better reducing power than aqueous-dried extracts. The antioxidant presents in the sample caused the reduction of $\mathrm{Fe}^{3+}$ to $\mathrm{Fe}^{2+}$ and thus proved its reducing power.

\section{CONCLUSIONS}

The present work was conducted to identify and assess the antioxidant activity of $R$. chinensis and $C$. macroptera. The antioxidant activity of each sample was compared with their freeze- and aqueous-dried extracts. It also revealed that the fruit extracts of plant possessed a significant antioxidant activity as it contains high phenolic content and flavonoids. It was observed that among all the extracts $R$. chinensis has a higher antioxidant activity as compared to C. macroptera juice. It was also found that freeze-dried fruits extract of all the sample exhibit better activity as compared to aqueous-dried extract.

Based on the results obtained, it can be concluded that the fruits extract possessed strong antioxidants. These activities may be attributed due to the presence of plant phytoconstituents such as flavonoids, steroids, tannins, and polyphenols suggesting its importance in various nutraceuticals and therapeutic agents. This suggests that the fruits can be viewed as a potential source of natural antioxidants that can provide valuable functional ingredients useful for the prevention of diseases related to oxidative stress, dietary supplements, functional food, nutraceuticals, etc.

At present, there are very few studies on these plants, so in-depth studies and further research will help in better understanding of its chemical constituent and potency which will, in turn, lead to the development of high potential therapeutic drugs as well as nutraceuticals or health supplements with lesser-known side effects.

\section{ACKNOWLEDGMENT}

The authors would like to acknowledge the Department of Biotechnology, Govt. of India, for providing all the requirements needed to conduct the study through IBT hub, RIPANS. We also acknowledge the Head, Department of Pharmacy, and Director, RIPANS, for providing necessary facilities in the institute.

\section{AUTHORS' CONTRIBUTIONS}

All authors contributed equally in the shape of this research work, analysis, and manuscript.

\section{CONFLICTS OF INTEREST}

The authors have no conflicts of interest. 


\section{AUTHORS FUNDING}

The funding was contributed by DBT's Institutional Level Biotech Hub (IBT hub), RIPANS, for the completion of this work.

\section{REFERENCES}

1. Brower V. Nutraceuticals: Poised for a healthy slice of the healthcare market. Nat Biotechnol 1998;16:728-31.

2. Trottier G, Boström PJ, Lawrentschuk N, Fleshner NE. Nutraceuticals and prostate cancer prevention: A current review. Nat Rev Urol 2010;7:21.

3. Arunkumar K, Chandrashekar KR. Phytochemical evaluation and in vitro antimicrobial and antioxidant studies of leaf and stem bark extracts of Polyalthia fragrans (Dalz.) bedd.-an endemic species of Western Ghats. Int J Pharm Pharm Sci 2017:9:20-4

4. World Health Organization. Traditional Medicine; Growing Needs and Potential, WHO Policy Perspective on Medicines. Geneva: World Health Organization; 2002. p. 1-9.

5. Nutraceuticals-global-market Outlook (2017-2026). Available from: https://www.researchandmarkets.com/reports/4655766/nutraceuticalsglobal-market-outlook-2017-2026. [Last accessed on 2019 Nov 16].

6. Prabu SL, Suriyaprakash TN, Kumar CD, Kumar SS. Nutraceuticals, and their medicinal importance. Int J Health Allied Sci 2012;1:47.

7. Valko M, Leibfritz D, Moncol J, Cronin MT, Mazur M, Telser J. Free radicals and antioxidants in normal physiological functions and human disease. Int J Biochem Cell Biol 2007;39:44-84

8. Sutar RC, Kalaichelvan VK. Evaluation of antioxidant activity of leaf extracts of Holoptelea integrifolia (Roxb) planch. Int J Appl Pharm 2014;6:6-8.

9. Sato M, Ramarathnam N, Suzuki Y, Ohkubo T, Takeuchi M, Ochi H. Varietal differences in the phenolic content and superoxide radical scavenging potential of wines from different sources. J Agric Food Chem 1996;44:37-41.

10. Shukla V, Vashistha M, Singh SN. Evaluation of antioxidant profile and activity of amalaki (Emblica officinalis), spirulina and wheat grass. Indian J Clin Biochem 2009;24:70-5.

11. Lalawmpuii R, Lalhriatpuii TC, Sailo L, Lalengliani K, Ghosh SK. Qualitative phytochemical screening and evaluation of in-vitro antioxidant activity of Callicarpa arborea roxb, an ethnomedicinal plant of Mizoram, Northeast India. Asian J Pharm Clin Res 2015;8:202-5.

12. Chang CC, Yang MH, Wen HM, Chern JC. Estimation of total flavonoid content in propolis by two complementary colorimetric methods. J Food Drug Anal 2002;10:178.

13. Foti M, Piattelli M, Baratta MT, Ruberto G. Flavonoids, coumarins, and cinnamic acids as antioxidants in a micellar system. Structure-activity relationship. J Agric Food Chem 1996;44:497-501.

14. Irda F, Evelyne N, Komar RW. In vitro antioxidant activities, total flavonoid, phenolic and carotenoid content from various extracts of four species Asteraceae herb. Int J Pharm Pharm Sci 2017;7:192-7.

15. Siddaraju MN, Dharmesh SM. Inhibition of gastric $\mathrm{H}+, \mathrm{K}+-\mathrm{ATPase}$, and Helicobacter pylori growth by phenolic antioxidants of Curcuma amada. J Agric Food Chem 2007;55:7377-86

16. Brand-Williams W, Cuvelier ME, Berset CL. Use of a free radical method to evaluate antioxidant activity. LWT Food Sci Technol 1995;28:25-30.

17. Wong WC. Evaluation of Natural Phenolic Antioxidants in Traditional Chinese Medicines as Carbohydrate Absorption Modulators for Potential Development of Anti-hyperglycemic Functional Foods. Hong Kong: HKU Theses Online (HKUTO); 2013.

18. Hasan MM, Hasan R, Al Mahmud MR, Islam MG. Protective effect of Citrus macroptera fruit pulp juice rendering Nrf2-pathway against cisplatin-induced genotoxicity. J Appl Pharm Sci 2018;8:67-71.

19. Soni A, Sosa S. Phytochemical analysis and free radical scavenging potential of herbal and medicinal plant extracts. J Pharmacogn Phytochem 2013;2:22-9.

20. Oboh G, Akinyemi AJ, Ademiluyi AO. Antioxidant and inhibitory effect of red ginger (Zingiber officinale var. Rubra) and white ginger (Zingiber officinale Roscoe) on $\mathrm{Fe} 2+$ induced lipid peroxidation in rat brain in vitro. Exp Toxicol Pathol 2012;64:31-6. 